\title{
Screening of Single Nucleotide Polymorphism in CD95 (APO-1/FAS) Promoter Region (G-1377A) in Children with Acute Leukemia
}

\author{
Dilara Fatma Akin Bali1 ${ }^{*}$, Didem Torun 0zkan², Ahmet Emin Kurekçi ${ }^{3}$, Nejat Akar ${ }^{4}$ \\ ${ }^{1}$ Faculty of Medicine, Medical Biology, Nigde Omer Halisdemir University, Nigde, Turkey \\ ${ }^{2}$ Vocational School of Health Service, Okan University, Istanbul, Turkey \\ ${ }^{3}$ LOSANTE Children's and Adult Hospital, Ankara, Turkey \\ ${ }^{4}$ TOBB-ETU Hospital, Ankara, Turkey \\ Email: *dilarafatmaakin@gmail.com
}

How to cite this paper: Bali, D.F.A., Ozkan, D.T., Kurekçi, A.E. and Akar, N. (2018) Screening of Single Nucleotide Polymorphism in CD95 (APO-1/FAS) Promoter Region (G-1377A) in Children with Acute Leukemia. Open Access Library Journal, 5: e4385. https://doi.org/10.4236/oalib.1104385

Received: January 29, 2018

Accepted: March 6, 2018

Published: March 9, 2018

Copyright $\odot 2018$ by authors and Open Access Library Inc.

This work is licensed under the Creative Commons Attribution International License (CC BY 4.0).

http://creativecommons.org/licenses/by/4.0/

\section{(c) (i) Open Access}

\begin{abstract}
CD95 is a cell surface receptor involved in apoptotic signal transmission. Deregulation of this pathway results in down regulation of apoptosis and subsequent persistence of a malignant clone. A single nucleotide polymorphism (SNP) resulting in guanine-to-adenine $(\mathrm{G}>\mathrm{A})$ transition in the CD95 promoter region (position -1377) is thought to reduce stimulatory protein 1 (SP1) transcription factor binding and decrease CD95 expression. The purpose of this study was to examine a genetic polymorphism in the core promoter of CD95 is associated with the frequency. G-1377A in the CD95 promoter region was genotyped by polymerase chain reaction and restriction endonuclease analysis and sequenced of the CD95 gene (Beckman Coulter, USA). Among 146 patients, CD95 G-1377A (rs2234767) SNP carriers frequencies has been identified as $25 \%$ GA (n:37) and AA $4 \%$ (n:6), respectively. This polymorphism of the distribution of the CD95 gene in acute leukemic children will be a guide for future studies.
\end{abstract}

\section{Subject Areas}

Hematology

\section{Keywords}

Acute Lymphoblastic Leukemia, Acute Myeloblastic Leukemia, CD 95

Polymorphism 


\section{Introduction}

The CD95 (Apo-1/Fas) receptor-ligand system is one of the key regulators of apoptosis and is particularly important for the maintenance of lymphocyte homeostasis. The CD95 receptor (also termed Apo-1 or FAS) is a type I transmembrane protein which belongs to the tumor necrosis factor receptor superfamily [1]. In the human, germline and somatic mutations of the CD95 gene are associated with a high risk of both lymphoid and solid tumors. The CD95 receptor is expressed in the majority of human cells, and signals apoptosis upon interaction with the CD95 ligand [2]. Binding to the receptor by the CD95 ligand triggers receptor trimerization and subsequent assembly of the death-inducing signaling complex [3]. This mechanism of CD95 mediated apoptosis is believed to be involved in the removal of autoreactive lymphocytes during normal development of the immune system [4]. Dysregulation of this pathway is believed to result in down regulation of apoptosis, allowing subsequent persistence of a malignant clone [5]. Germline mutations or deletions within CD95, resulting in a loss or a reduction in receptor function, have been shown to cause autoimmune lymphoproliferative syndrome as well as an overall increased risk of hematological malignancies [6]. CD95 expression levels may also be affected by mutations or polymorphisms in the promoter region of $\mathrm{CD} 95$, when they affect the transcription binding sites. A SNP resulting in guanine-to-adenine $(G>A)$ transition in the CD95 promoter region occurs at position -1377, affecting a stimulatory protein 1 (SP1) transcription factor binding site [5]. An adenine residue at this position significantly reduces SP1 binding compared to guanine residue, causing a decrease in CD95 expression [5]. Many cell types express CD95 including cells of B-lineage [7], T-lineage [8] and acute leukemias. Myeloblasts are known to express high levels of CD95, and functional deficiencies of CD95 signaling have been shown to be important in several subtypes of acute myeloid leukemia (AML), providing further evidence for CD95-mediated apoptosis in the etiology of AML [9]. CD95 expression has been associated with a better prognosis in B-cell lymphomas and with responsiveness to chemotherapy in AML, whereas most primary T-cell leukemias are constitutively resistant against CD95-induced apoptosis [10]. The purpose of the study is to investigate CD95 G-1377A SNP in patients with acute leukemia and to determine the frequency of the polymorphism between patients and healthy individuals.

\section{Material and Methods}

Study population consisted of 248 patients and control individuals aged between 1 and 15 years, who were admitted to Losante Children's and Adult Hospital. The study group consists of 64 males and 82 females. The patient blood was collected from Losante Children Hospital, Turkey. One hundred forty-six children with leukemia were included in the study. Healthy groups were selected among healthy unrelated subjects from Turkey (n:102). An informed written consent was obtained from all the patients' parents. The study is carried out in accordance 
with the code of Ethics of the World Medical Association (Declaration of Helsinki) for experiments involving humans.

We evaluated 146 patients $(\mathrm{n}=146)$ with leukemia and 102 control samples ( $\mathrm{n}$ $=102$ ) with using PCR (Polymerase chain reaction) analysis and DNA sequencing study (Beckman Coulter, USA). When selecting control samples, the ones with leukemia were omitted. Healthy groups were selected among healthy unrelated subjects from Turkey (n: 102). An informed written consent was obtained from all the patients' parents. Of patients group, 123 children (84\%) of the patients were diagnosed as acute lymphoblastic leukemia (ALL), 13 (9\%) as acute myeloblastic leukemia (AML), 7 (5\%) as biphenotypic leukemia, and $3(2 \%)$ acute promyelocytic leukemia (APL). DNA was extracted from blood samples using conventional methods. Primers were employed according to the previously described method using the primers F-5'-TGTGTGCACAAGGCTGGCGC-3' and R-5'-TGCATCTGTCACTGCACTTACCACCA-3' (11). PCR program was run at $94^{\circ} \mathrm{C}$ for $10 \mathrm{~min}$, followed by $35 \mathrm{cycles}$ of $\left(94^{\circ} \mathrm{C}\right.$ for $30 \mathrm{~s}, 62^{\circ} \mathrm{C}$ for $30 \mathrm{~s}$ and $72^{\circ} \mathrm{C}$ for $1 \mathrm{~min}$ ) and final extension at $72^{\circ} \mathrm{C}$ for $5 \mathrm{~min}$. Amplification was confirmed by electrophoresis on $2 \%$ agarose gel. PCR products. The restriction enzyme BstUI (Fermantas, Lithuania) was used to detect the CD95, G-1377A SNP, in which the loss of a BstUI restriction site occurs in the polymorphic $\mathrm{G}$ allele. The homozygous polymorphic GG genotype produces a single band representing 118-bp fragment. The homozygous AA wild-type genotype produces 2 bands of 98-bp and 20-bp fragments, and the heterozygous AG genotype produces 3 bands $(118,98$, and $20 \mathrm{bp})$. BstUI-digested PCR products were separated on $4 \%$ agarose gels, stained with ethidium bromide, and visualized under UV light. Furthermore, final confirmation of G-1377A genotyping assay was obtained in 40 samples using DNA sequencing (Beckman Coulter CEQ8000, USA.) and analyzed using the Sequence Analysis program.

Statistical analyses were performed with SPSS 15.0 (SPSS IBM, USA). Chi-square test, independent sample $t$-test, or Mann-Whitney $U$-test, as appropriate for the type of data being analyzed, were used to assess the statistical significance of the difference between the two groups. P values less than 0.05 were considered statistically significant.

\section{Results}

Single nucleotide polymorphisms in the promoter of Fas gene at positions -1377 G/A and $-670 \mathrm{~A} / \mathrm{G}$ may affect its expression and play an important role in the leukemogenesis [11]-[18]. Promotor region of CD95 gene analysis of Turkish patients with acute leukemia revealed the prevalance of CD95 G-1377A (rs2234767) polymorphisms were determined for 146 childhood leukemia patients. Of the 146 childhood leukemia patients, we identified 37 (25\%) were heterozygous and $6(4 \%)$ were homozygotes. 5 patients diagnosed with ALL and one patient diagnosed with biphenotypical acute leukemia among CD95 G-1377A Homozygous patients. All previous investigations have shown that the 
mutation caused the CD95 downregulation. A revision has been made on the subject in the conclusion section of the article. The same experiments have not been repeated in the literature due to the fact that studies related to the subject have been found.

Heterozygous patients diagnosed with 29 ALL, 4 AML, 3 biphenotypic acute leukemia and one patient diagnosed with APL. $31 \%$ of 13 patients with AML (n: 4) were found as heterozygous, while heterozygous percentage of ALL patients was $24 \%$ (n: 29). The prevalence of CD95 G-1377A polymorphisms was determined for 102 healthy individuals. Among 102 healthy individuals, CD95 G-1377A polymorphisms were found in 12 cases (11.7\%) (Table 1 and Table 2). There were significant differences in the genotype frequency for CD95 G-1377A polymorphism between the groups (Table 2).

\section{Discussion}

In the literature, numerous studies researched in different population, showed correlation on between genetic polymorphisms of CD95 in different diseases. However, there are inadequate studies in development of childhood leukemia. Functional G-1377A SNP in CD95 gene that the development of apoptosis and cancer plays an important role has been reported in many studies. This SNP was reported that the risk of developing AML is associated with the G-1377A polymorphism in the promoter region of the CD95 gene, which affects a SP1 transcription factor binding site. Valibegi et al. reported that their study showed no contribution of CD95 genotypes at positions -670 and -1377 to risk for children with ALL (12). Beltinger et al. have displayed the presence of mutations in leukemic blasts of some T-ALL patients. In the CD95 promoter region, the two

Table 1. Genotype distributions in childhood leukemia patients and healthy groups.

\begin{tabular}{cccc}
\hline Patients with leukemia (n: 146) & $\begin{array}{c}\text { Wild-type } \\
\text { N (\%) }\end{array}$ & $\begin{array}{c}\text { Heterozygous } \\
\text { N (\%) }\end{array}$ & $\begin{array}{c}\text { Homozygous } \\
\text { N (\%) }\end{array}$ \\
\hline Healthy Individuals (n: 102) & $90(88.2)$ & $12(11.7)$ & 0 \\
ALL (n: 123) & $89(72.35)$ & $29(32.5)$ & $5(4.06)$ \\
AML (n: 13) & $9(69.23)$ & $4(30.76)$ & - \\
Biphenotypical acute leukemia (n: 7) & $3(42.85)$ & $3(42.85)$ & $1(14.28)$ \\
APL (n: 3) & $2(66.6)$ & $1(33.3)$ & - \\
\hline
\end{tabular}

Table 2. Comparison of CD95 G1377A in between childhood leukemia and healthy groups.

\begin{tabular}{ccccc}
\hline $\begin{array}{c}\text { CD95 } \\
\text { G-1377A }\end{array}$ & $\begin{array}{c}\text { Healthy } \\
\text { Individuals } \\
\mathbf{n}=\mathbf{1 0 2}\end{array}$ & $\begin{array}{c}\text { Patient with } \\
\text { Leukemia } \\
\mathbf{n}=146\end{array}$ & OR & p value \\
\hline Wild Type & 90 & 102 & 1 & \\
Heterozygous & 12 & 37 & $2.72(1.33-5.53)$ & 0.014953 \\
Homozygous & 0 & 7 & $6.17(0.74-51.1)$ & 0.105239 \\
\hline
\end{tabular}


positions -670 and -1377 , due to their binding capacity to transcription factors and regulating the level of gene expression have been studied in different populations [13].

Individuals homozygous for adenine at G-1377A are almost twice as likely to develop AML, with heterozygotes having an intermediate risk compared with individuals homozygous for guanine. Sibley et al. have reported a significantly increased risk of developing AML in adult patients with heterozygous GA and homozygous AA genotypes at position -1377 bp [14]. In this study, between CD95 SNP and clinical data in patients with acute leukemia in order to find a value in a statistically significant number of cases is expected to increase. However, there was no evidence of an increased risk of AML associated with the G-1377A polymorphism.

To CD95, gene expression values higher than P75, which is gene expression values above the 75th percentile were significantly associated with greater event-free-survival, among the ALL children studied in uni- and multivariable analysis and with a lower chance of an unfavorable event [15]. In childhood pre-B ALL, higher CD95 antigen expression was associated with longer survival in complete remission [15] [16]. Other studies however, did not find any association between constitutive expression or CD95 function and prognosis in ALL [16] [17] [18].

When SNPs detected in the promoter region of the gene probe are assessed in databases and supported by literature surveys, it is very clear that this is the guideline for disease progression and further studies. Our work carries scientific importance in three ways: First, the screened polymorphism in this article seems to be the first results of studied genes in children with leukemia patients. Second, we found that G-1377A polymorphism may be associated with development of leukemia as genetic risk factor. Three, the present study are helpful to provide knowledge to other researchers about included gene variations analyzed in this pathway in childhood leukemia patients.

\section{Conclusion}

In conclusion, the results of the current study showed that CD95 gene polymorphisms might have an implication in pediatric leukemias, however, large scale studies are needed. In addition, studies aiming to define the functionality of CD95 gene polymorphism will help clarify the importance of variants at this site.

\section{References}

[1] Oehm, A., Behrmann, I., Falk, W., Pawlita, M., Maier, G., Klas, C., Li-Weber, M., Richards, S., Dhein, J., Trauth, B.C., et al. (1992) Purification and Molecular Cloning of the APO-1 Cell Surface Antigen, a Member of the Tumor Necrosis Factor/Nerve Growth Factor Receptor Superfamily. Sequence Identity with the Fas Antigen. Journal of Biological Chemistry, 267, 10709-10715.

[2] Leithauser, F., Dhein, J. and Mechtersheimer, G. (1993) Constitutive and Induced Expression of APO-1, a New Member of the Nerve Growth Factor/Tumor Necrosis 
Factor Receptor Superfamily, in Normal and Neoplastic Cells. Laboratory Investigation, 69, 415-429.

[3] Muschen, M., Warskulat, U. and Beckmann, M.W. (2000) Defining CD95 as a Tumor Suppressor Gene. Journal of Molecular Medicine, 78, 312-325.

https://doi.org/10.1007/s001090000112

[4] Watanabe-Fukunaga, R., Brannan, C.I., Copeland, N.G., Jenkins, N.A. and Nagata, S. (1992) Lymphoproliferation Disorder in Mice Explained by Defects in Fas Antigen That Mediates Apoptosis. Nature, 356, 314-317. https://doi.org/10.1038/356314a0

[5] Mehta, PA., Gerbing, R.B., Alonzo, T.A., Elliott, J.S., Zamzow, T.A., Combs, M., Stover, E., Ross, J.A., Perentesis, J.P., Meschinchi, S., Lange, B.J. and Davies, S.M. (2008) FAS Promoter Polymorphism: Outcome of Childhood Acute Myeloid Leukemia. A Children's Oncology Group Report. Clinical Cancer Research, 14, 7896-7899.

[6] Rieux-Laucat, F., Le Deist, F., Hivroz, C., Roberts, I.A., Debatin, K.M., Fischer, A. and de Villartay, J.P. (1995). Mutations in Fas Associated with Human Lymphoproliferative Syndrome and Autoimmunity. Science, 268, 1347-1349.

https://doi.org/10.1126/science.7539157

[7] Owen-Schaub, L.B., Meterission, S. and Ford, R.J. (1993) Fas/APO-1 Expression and Function on Malignant Cells of Hematologic and Non-Hematologic Origin. Journal of Immunotherapy, 14, 234-241. https://doi.org/10.1097/00002371-199310000-00011

[8] Debatin, K.M. and Krammer, P.H. (1995) Resistance to APO-1 (CD95) Induced Apoptosis in T-ALL Is Determined by a BCL-2 Independent Antiapoptotic Program. Leukemia, 9, 815.

[9] Komada, Y., Zhou, Y.W., Zhang, X.L., Xue, H.L., Sakai, H., Tanaka, S., Sakatoku, H. and Sakurai, M. (1995) Fas Receptor (CD95)-Mediated Apoptosis Is Induced in Leukemic Cells Entering G1B Compartment of the Cell Cycle. Blood, 86, 3848-3860.

[10] Beltinger, C., Kurz, E., Böhler, T., Schrappe, M., Ludwig, W.D. and Debatin, K.M. (1998) CD95 (APO-1/Fas) Mutations in Childhood T-Lineage Acute Lymphoblastic Leukemia. Blood, 91, 3943-3951.

[11] Hu, Z., Li, C., Chen, K., Wang, L.E., Sturgis, E.M., Spitz, M.R. and Wei, Q. (2008) Single Nucleotide Polymorphisms in Selected Apoptotic Genes and BPDE-Induced Apoptotic Capacity in Apparently Normal Primary Lymphocytes: A Genotype-Phenotype Correlation Analysis. Journal of Cancer Epidemiology, 2008, Article ID: 147905. https://doi.org/10.1155/2008/147905

[12] Valibeigi, B., Amirghofran, Z., Golmoghaddam, H., Hajihosseini, R. and Kamazani, F.M. (2014) Fas Gene Variants in Childhood Acute Lymphoblastic Leukemia and Association with Prognosis. Pathology \& Oncology Research, 20, 367-374. https://doi.org/10.1007/s12253-013-9705-2

[13] Sibley, K., Rollinson, S., Allan, J.M., Smith, A.G., Law, G.R., Roddam, P.L., Skibola, C.F., Smith, M.T. and Morgan, G.J. (2003) Functional FAS Promoter Polymorphisms Are Associated with Increased Risk of Acute Myeloid Leukemia. Cancer Research, 63, 4327-4330.

[14] Mata, J.F., Silveira, V.S., Mateo E.C., Cortez, M.A, Queiroz, R.G., Yunes, J.A. and Lee, M.L. (2010) Low mRNA Expression of the Apoptosis-Related Genes CASP3, CASP8, and FAS Is Associated with Low Induction Treatment Response in Childhood Acute Lymphoblastic Leukemia (ALL). Pediatric Blood \& Cancer, 55, 100-107. 
[15] Baryshnikov, A., Polosukhina, E.R. and Tupitsin N.N. (1999) CD95 (FAS/APO-1) Antigen Is a New Prognostic Marker of Blast Cells of Acute Lymphoblastic Leukaemia Patients. Advances in Experimental Medicine and Biology, 457, 251-258. https://doi.org/10.1007/978-1-4615-4811-9_27

[16] Aref, S., Salama, O. and Al-Tonbary. Y. (2004) Assessment of Bcl-2 Expression as Modulator of Fas Mediated Apoptosis in Acute Leukemia. Hematology, 9, 113-121. https://doi.org/10.1080/1024533042000205496

[17] Wuchter, C., Karawajew, L. and Ruppert, V. (1999) Clinical Significance of CD95, Bcl-2 and Bax Expression and CD95 Function in Adult de Novo Acute Myeloid Leukemia in Context of P-Glycoprotein Function, Maturation Stage, and Cytogenetics. Leukemia, 13, 1943-1953. https://doi.org/10.1038/sj.leu.2401605

[18] Wuchter, C., Karawajew, L. and Ruppert, V. (2000) Constitutive Expression Levels of CD95 and Bcl-2 as Well as CD95 Function and Spontaneous Apoptosis in Vitro Do Not Predict the Response to Induction Chemotherapy and Relapse Rate in Childhood Acute Lymphoblastic Leukaemia. British Journal of Haematology, 110, 154-160. https://doi.org/10.1046/j.1365-2141.2000.02147.x 